\title{
Dynamic Evaluation Method of English Writing for College Students
}

\author{
Xiaoyi Liu \\ Foreign Language Department of Jilin Business and Technology College \\ Changchun City, China \\ 1xyruthy@163.com
}

\begin{abstract}
In college English learning, writing ability represents the highest capacity, which is one of the important measures of college students' English level. However, how to effectively conduct college English writing teaching is a very important subject for teachers. This paper discusses the dynamic assessment in college English writing teaching. Teacher's involvement helps to improve student achievement, which not only provides a reference for dynamic evaluation of English writing teaching, but also has certain positive meaning for foreign language teaching reforming and breaking through the bottleneck of teaching foreign language writing.
\end{abstract}

Keywords-college english; writing teaching; dynamic assessment; teacher's intervention

Over the years, summative tests prevail in college English writing classes all over mainland China. With uniform content and mechanical criteria, such assessment modes focus too much on the learning results, ignoring the learning process, thus they are not conducive to promoting the development of the students' writing competence. Issued by the Ministry of Education in 2007, College English Curriculum Requirements specifically supplement the contents of the teaching evaluation, with emphasis on the procedure and development of assessment. Therefore, it is high time to explore and establish a new assessment mode in college English writing class.

In traditional teaching class of college English writing, behaviorism teaching mode of "stimulus - responsestrengthening" is basically used ${ }^{[1]}$ namely "teacher's class arrangement of composition-showing model essay or writing template-students completing and submittingteacher's fully or partially correcting-teacher's commenting typical mistakes or praising excellent writing". This writing teaching mode considers the teacher as the center of class and the ultimate test as dominance. However, the evaluation puts too much emphasis on the results and ignores the students' learning process, so that the students have been in a position of passive learning and lack of initiative to find the problem, as a matter of course, students never take the initiative or enthusiasm to modify the composition, as time passes, the development of students' writing ability will be hindered. ${ }^{[2]}$ With the development of information technology and the response to the ministry of education, many colleges and universities are trying to introduce the network model in English teaching. This model can achieve timely feedback and provide the best resources and technical support for students.

\section{DYNAMIC ASSESSMENT}

Dynamic assessment was derived from Sociocultural Theory of Mind(SCT) put forward by the famous Russian psychologist Vygotsky, its core lies in the concept of Zone of Proximal Development(ZPD). Ygotsky thought that the level of the students can be divided into two kinds, current levels and potential levels, which is the potential can be obtained through the teaching, so teachers should aim at arousing students' interest and potential in the teaching process, constantly set learning task according to the specific situation of the students, improve learning difficulty and make their abilities develop gradually. From dynamic assessment's perspective, it is focused on the view of the individual learning ability, because any type will be subject to a certain point in time. ${ }^{[3]}$

Dynamic evaluation is the interaction between a series of evaluation passers and learners, aiming to explore and discover evaluation methods of the development of learners' potential ability. It is a kind of interactive evaluation method with many research directions. The theory emphasizes the role of teaching and teachers' leading position, and also considers the teacher as the promoter of students' psychological development. Dynamic evaluation is to understand the students dynamic cognitive process, the characteristics of learning transfer and potential cognitive ability. "Intervention and evaluation of teaching" is the most unique characteristics of dynamic assessment. At the same time, the dynamic assessment also stresses the social culture and the influence of non-intelligence on individual potential. The introduction of the concept of dynamic assessment firstly is the recognition of the evaluation concept, so, effective evaluation methods should not only make an objective, fair and comprehensive observation and summary for the current level of the assessed individuals, but also forecast its possible development and try to contribute to the perfect development. ZPD will therefore fully focus on the development of individual potential and make the evaluation not only focus on the past but also focus on the future. ${ }^{[4]}$ 


\section{TEACHER'S INTERVENTION METHOD}

DA theory emphasizes the inseparability of evaluation and teaching, which believes that teaching intervention plays an important role in the comprehensive evaluation of students' ability and teaching intervention at the same time promotes the development of students' ability. On the other hand, in order to make teaching guide the development of the students' ability to the largest extent, a comprehensive examination of students' individual ability is also a must. Therefore, evaluation and teaching is a dialectical development oriented system. ${ }^{[5]}$ According to DA criterion, A comprehensive description of the student writing ability can't just rely on observing students' performance in a single writing behavior, but needs to be implemented through specific forms of personal activities or social interaction activities in the process of writing.

In the implementation of the whole evaluation model, the teachers need to focus on students' possible difficulties in the writing process, and design the various intervention support may be needed by students. Through observing the student's response to the teaching intervention activity, teachers also need to make more sensitive to the students' writing ability, on the basis of it, the design of intervention support activity in next step can be carried through. The performance of the students in each step, in turn, tests the effectiveness of the teacher's teaching intervention in a timely manner, and constantly improves the involvement of teaching activities. This evaluation pattern can make a common assessment in both sides of teaching and learning and promote the incessant teaching progress on both sides.

\section{A. Pre-writing intervention}

Pre-writing intervention is also known as "collective free discussion". It is an inspiration thinking method proposed by the American educator Osborne for the first time in 1939, whose formal application began in 1953. Now this method has become an unlimited free association and discussion method for synonyms, whose purpose is to stimulate the collective wisdom and new ideas. Through this method, a lot of new ideas and creativity are quickly produced. Therefore, this method is a kind of creative activity with practical significance. ${ }^{[6]}$

As a collective and creative method to solve problems, "collective free discussion" has a great practical value for the foreign language writing teaching. Through the organization of most commonly seen activities, it can effectively improve their creativity and ability to enrich the content of the writing and produce a composition of high quality. Because "collective free discussion" is a kind of efficient way of cultivating creativity, so English teachers should be create a free and relaxing "collective discussion" atmosphere for students' writing, which is embodied in the following two aspects.

\section{1) Choose topic.}

Topic and title are the key to writing. Before writing, teachers should give certain topics and materialize the scope of writing with realistic significance. Then the teacher should ask the students to be divided into groups and draw up a title according to the given topics. Students in each group can present and share the related knowledge and writing skills they are interested with other students. Through actively seeking for topics and materials, each member of groups can show out points of view. Based on the cooperation of the group, the group leader lists out the key points involved in the discussion. Then, the group leader reports the points of view in his group, in the process, the other students can put forward any problems and suggestions during the leader's presentation. According to the overall situation of students, the teacher can timely put forward the contents which are not involved in discussion and presentation. At the end of the pre-writing process, the teacher evaluates the titles of the proposed by the students in each group, in particular to praise students who are excellent enough to put forward in-depth topic. ${ }^{[7]}$

2) Clarify article context and select the expression.

The two aspects are the most frequently problems encountered by Chinese students when writing English composition. This requires teachers to teach students how to formulate the title according to the requirement, list the outline, seize the key points and get the useful information, so as to be fully prepared before writing. Students can try to list words and phrases related to the composition and form phrases into a sentence, then, develop related sentences of each paragraph in accordance with the order rearrangement and pay attention to the transition words of each paragraph, forming a complete composition. But this is only the first draft, students also need to revise and improve the faithfulness, expressiveness, elegance of their composition.

\section{B. Writing intervation}

Writing intervention means simultaneous assessment and interaction. Because writing is a complex and cognitive activity and advanced form and is also a kind of written form that the authors express their emotions and influence others to feel the process, so the aim of English writing is not only to teach students how to set the title, but also to pay attention to the choice of words, grammar, cultural background and discourse structure, etc. ${ }^{[8]}$ In this way, students can really write informative compositions. Vygotsky thought that mutual cooperation has a very important role in promoting development of students' writing, therefore, in addition to the choice of topics, overall planning, macro and micro level and the use of expressions, teachers should also cultivate the students' consciousness of cooperation, promoting the interaction between students and guiding students in the process of writing, that is to say, learning others' advantages makes up for self-weaknesses.

\section{Intervation of Teacher's Role}

Intervation of teachers' role is also known as "guidance and inspiration". In the entire operation process of writing, teacher must ensure that the students are centered. Teacher can also help the students learn to communicate with other teachers and classmates to establish the students' writing ability in a timely manner. A teacher should appropriately participate in the students' learning process. In the process 
of interaction and communication with students, teachers are also able to evaluate students' performance at ordinary times. This assessment can urge the students who are silent in class to have a positive performance and make up for their mistakes. If teacher finds students' learning foundation to be very weak and lack of preview or preparation before writing class, they should encourage students to actively read books and visit useful websites. Teachers' intervention process should be continuous from easiness to difficulty. Therefore, writing intervention in writing class needs to be elaborately designed in order to let students realize the common development in "the zone of proximal development". [9]

Throughout the intervention in the operation of the evaluation of teachers, teachers in beginning bear the most of the work, not only to intervene before writing, must also intervene in the process of writing, in addition, teachers' role of intervention is also very important. With the improvement of students' writing ability, teachers gradually reduce the frequency and the degree of intervention, so that the students can gradually be independent on doing writing task. Teachers works always adhere to the systematical, continuous and evolutionary principles, ${ }^{[10]}$ f rom easy to difficult, and review from time to time, in order to ensure that the design of the writing task and intervention in English teaching class become successful and efficient in the area of the students' ZPD, which is because the students individual ability and corresponding demand always happen suddenly, needing teachers at the right time to let the students become independent, give full play to the writing resources construction, policy guidance, their own way of collaboration between teachers and students and students "social cultural tool" of "intervention" function, making these tools adjust and comb the "access" to inspire students" behavior and guide students' to set goals.

\section{CONCLUSION}

To sum up, in the college English writing teaching, "teachers' intervention" strategy is a kind of effective way to improve students' English writing ability and stimulate students interest in learning. In the process of teachers' involvement, teacher's professional knowledge have been continuously deepened and promoted. In this process, teachers and students can get the three-dimensional theory and professional knowledge. More importantly, the intervention process can help students to enhance understanding and memorizing theoretical knowledge, apply theory to practice and improve the comprehensive ability to use knowledge in English writing. Teachers' intervention strategy is the most important feature of breakthrough in the teaching material, classroom space and the limitation of the book so as to further strengthen the teachers "interactivity and diversity" dynamic evaluation of the teaching process, which can really help students to improve writing skills. ${ }^{[11]}$
Intervention mode is an effective way to stimulate the knowledge in textbooks. In the process of teachers' intervention, teachers' professional knowledge can be constantly deepen and improved and students can strengthen their theoretical knowledge and put it into practice. The most crucial feature of teacher's intervention mode is that it breaks through the restriction of textbook content, classroom space and textbook teaching purpose, which further improves the interactivity and flexibility of teaching, fundamentally improving students' writing ability.

Of course, in order to really introduce the dynamic assessment and intervention strategies into college English writing teaching, it also needs the scholars in the field further explore and develop the relevant theories, so as to realize the comprehensive reform of English writing teaching in college, really perfect evaluation of professional English writing teaching, and improve the assessment standard of English writing teaching, and further make it develop towards a more professional, scientific and normative direction.

\section{REFERENCE}

[1] Antón, M. Dynamic assessment of advanced foreign language learners [R]. Paper presented at the American Association of Applied Linguistics, Washington D. C., 2003.

[2] Budoff, M. The validity of learning potential assessment [A]. In Dynamic Assessment: An Interactive Approach to Evaluating Learning Potential [C]. C. S. Lidz (Ed.) New York: The Guilford Press, 1987

[3] Carlson, J. S. \& K. H. Wiedl. The validity of dynamic assessment [A] In C. S. Lidz \& J. G. Elliott (Eds.). Dynamic assessment: Prevailing models and applications [C]. Amsterdam: JAI/Elsevier Science, 2000: 681-712

[4] Donato, R. Collective scaffolding in second language learning [A].. In J. P. Lantolf and G. Appel (Eds.),Vygotskyan approaches to second language research [C]. Norwood, NJ: Ablex Publishing Corporation, 1994: 35-56.

[5] Lei, Xiao. Exploring a sociocultural approach to writing strategy research: Mediated actions in writing activities [J]. Journal of Second Language Writing, 2008, (17): 217-236.

[6] Wiedl, K. H., J. Güthke, \& S.Wingenfeld, Dynamic assessment in Europe: historical perspectives [A], In Jerry S. Carlson (Eds.) Advances in Cognition and Educational Practice: European Contributions to Dynamic Assessment [C], by JAI Press Inc., 1995, (3): $33-82$.

[7] Wertsch, J. Vygotsky and the Social Formation of Mind [M] Cambridge, MA.: Harvard University

[8] Press, 1985.

[9] Zhang Yanhong. The dynamic evaluation research of college English writing teaching[D]. Shanghai International Studies University ,2012.

[10] Wu Qi. Dynamic evaluation of English writing teachingTeacher's intervation exploration[J]. English Teacher, 2013, 05:23-28

[11] Sun Sainan. The influence of dynamic assessment in college English writing teaching [J].Journal of Kaifeng Institute of Education ,2014,08:135-136 